\title{
Global evidence on the effect of point-of-sale display bans on smoking prevalence
}

\author{
Yanyun $\mathrm{He}_{1}{ }^{1}$ Ce Shang ${ }_{1}{ }^{2}$ Jidong Huang, ${ }^{3}$ Kai-Wen Cheng, ${ }^{1,2}$ Frank J Chaloupka ${ }^{1,2}$
}

\begin{abstract}
'University of Illinois, Chicago, Illinois, USA

${ }^{2}$ Institute for Health Research and Policy, University of Illinois,

Chicago, Illinois, USA

${ }^{3}$ School of Public Health,

Tobacco Center of Regulatory

Science, Georgia State

University, Atlanta, Georgia,

USA
\end{abstract}

\section{Correspondence to}

Dr Ce Shang, Institute for Health Research and Policy, University of Illinois, Chicago, IL 60002, USA; cshang@uic.edu

Received 14 August 2017 Revised 29 November 2017 Accepted 7 December 2017 Published Online First

13 January 2018
Check for updates

To cite: He Y, Shang $C$, Huang J, et al. Tob Control 2018;27:e98-e104.

\section{ABSTRACT}

Background Since Iceland became the first country to impose a ban on point-of-sale (POS) tobacco product displays in 2001, 20 countries have implemented POS display bans as of 2016. This study examined the effect that POS display bans have on smoking prevalence.

Methods Data were sourced from Euromonitor International and the WHO MPOWER package for 2007-2014 from 77 countries worldwide. generalised linear models with country and year fixed effects were estimated to analyse the effect of POS display bans on smoking prevalence.

Results Having a POS display ban reduced overall adult daily smoking, male smoking and female smoking by about $7 \%, 6 \%$ and $9 \%$, respectively.

Conclusions Having a POS display ban is likely to reduce smoking prevalence and generate public health benefits.

\section{INTRODUCTION}

The WHO Framework Convention on Tobacco Control (WHO FCTC), a treaty with 181 parties worldwide, calls for comprehensive restrictions on tobacco marketing, promotion and sponsorship. ${ }^{1}$ As countries have implemented regulations banning advertising and promotion of tobacco products in traditional media outlets such as television, radio and outdoor billboards, tobacco companies increasingly market their products to customers at the point of sale (POS). POS displays (eg, product placement, brand exhibition and price discounts) have become an important competitive marketing strategy. ${ }^{2}$ In the USA, tobacco industry expenditures on cigarette POS advertising and promotion increased from \$76 million in 2011 to \$238 million in 2014. ${ }^{34}$ In Chile, the tobacco industry invests in making bigger and more attractive display cabinets for their products to attract shoppers and prompt impulse purchases. For example, to support new product launches and to better communicate with customers, small liquid-crystal display screens were installed in some stores. ${ }^{5}$

Seeing tobacco products can stimulate the desire to purchase and decrease thoughts about quitting. POS displays are associated with greater odds of impulse purchasing and the urge to purchase tobacco products. $^{6}$ Another study found that a small-to-moderate proportion of tobacco purchases were made on impulse, and approximately one-third of smokers agreed POS promotion made quitting smoking more difficult.

Iceland became the first country to impose a ban on POS advertising and displays in 2001 (online supplementary appendix). Since then, other countries have implemented POS display bans, including Canada (Manitoba became the first province to ban POS displays on January 2004, and as of January 2010, all provinces had followed suit), Thailand (September 2005), Belarus (January 2008), Ireland (July 2009), Australia (the first jurisdiction, the Australian Capital Territory, implemented in December 2009; and as of January 2012 all states and territories had a ban) and Norway (January 2010). In countries where POS display bans came into force, cigarettes may not be displayed in-store and consequently consumers are not permitted to browse or examine the cigarette brands/products on offer prior to purchase.

To date, 20 countries have implemented POS display bans (online supplementary appendix). However, the limited number of studies examining the effect of POS display bans on smoking behaviours has provided mixed results. In Canada and Iceland where POS display bans have been implemented, a decrease in youth and adult smoking prevalence was observed. ${ }^{89}$ The bans may have contributed to these reductions. However, without assessing other changes in the tobacco control environment, such as the implementation of other tobacco control strategies, the two existing observational studies could not determine conclusively whether POS display bans reduced smoking. Shang et al examined the association between POS advertising restrictions and smoking behaviours among youth using data from the Global Youth Tobacco Survey in 130 countries between 2007 and 2011. ${ }^{10} 11$ A POS advertising ban was significantly associated with reduced experimental smoking and smoking participation among youth.

Several studies examined the effect of POS displays on purchasing behaviours or the effect of POS display bans on exposure to tobacco product marketing. Wakefield et al found that $31 \%$ of smokers thought removal of POS displays would help them quit. ${ }^{12}$ Carter et al and Clattenburg et al also found strong evidence that POS displays prompted impulse buying of cigarettes and urges to smoke and undermined quit attempts. ${ }^{713}$

Li et al used longitudinal individual-level data from the International Tobacco Control survey to compare the variability in POS marketing restrictions in four Western countries: Australia and Canada, where POS display bans had been implemented, and the UK and the USA, where there were no such bans in place. ${ }^{14}$ They also examined the effect of POS marketing restrictions on adult smokers' exposure to tobacco product marketing and their cigarette purchasing behaviours. In countries where POS display bans were implemented, smokers reported exposure to tobacco marketing 
declined markedly. Smokers in countries without POS display bans were more likely to make unplanned purchases. A study in Norway observed before and after implementation of the POS display ban in January $2010^{15}$ found that compared with older people young people were more likely to be tempted by tobacco products when seeing them in the shop, and therefore, found it more difficult to choose a brand or buy tobacco products after the ban was implemented.

In contrast, an Irish study found no significant short-term change in smoking prevalence among adults within the first year following the implementation of a POS display ban. ${ }^{16}$ Quinn et al examined the economic impact of the POS display ban on cigarette sales in Ireland using aggregated actual sales data and found no statistically significant decline in cigarette pack sales following the implementation of the legislation. ${ }^{17}$

However, these existing studies either presented descriptive statistics or estimated associations between POS display bans and smoking behaviours, and as a result, did not analyse the causal impact of POS display bans on smoking. In addition, many countries have implemented a comprehensive set of tobacco control policies, such as tax increases, smoke-free air laws and graphic warning labels, as suggested by the WHO FCTC, which could be potential confounders when estimating the effect of POS display bans on smoking.

POS display bans are likely to affect smoking behaviour by cutting off an important communication channel with potential customers and providing a supportive environment for smokers to quit. ${ }^{18}$ However, to date, no studies in the peer-reviewed literature have assessed the impact of POS display bans on adult smoking across multiple countries. Using aggregated country-level longitudinal data from 77 countries in the world from 2007 to 2014, and a two-way fixed effects model, we analyse the causal link between POS display bans and smoking prevalence, accounting for the tobacco control environment and population demographic characteristics.

\section{DATA AND METHODS}

\section{Data and measures}

Outcome and policy variables: Euromonitor International

Information on smoking prevalence among the total adult population, male population and female population during 20072014 was gathered from Euromonitor International country reports. ${ }^{5}$ Adult smokers are defined as daily smokers who are older than the minimum legal smoking age in the country. The legal age for purchasing cigarettes in the 20 countries with POS display bans ranged from 16 to 19 years. Annual smoking prevalence was measured as percentage of daily smokers.

The status of POS display bans also came from Euromonitor International cigarette country reports. We constructed a variable ranging from 0 to 1 to measure exposure to POS display bans. If the POS display ban was a national ban and implemented throughout the year, the variable took a value of 1 , and if the ban did not exist in a country-year, this variable took a value of 0 . If the ban came into effect in mid-year, the value of the variable was a fraction between 0 and 1 corresponding to the length of the ban in that year. For example, if the display ban came into force in July, the variable took a value of 0.5 in the year it was implemented. In addition, since POS display bans in Australia and Canada started at the local level and gradually covered the entire countries, the exposure measure was further adjusted using the per cent of population covered by the ban. For the UK, where the POS display ban was first implemented in large stores in April 2012 and later expanded to all types of stores in April
2015, the exposure measure was adjusted using the proportion of cigarette sales in large stores among total sales revenues, during the period when only large stores were subject to POS display bans. The correlation between the provinces/states in Australia and Canada who had the ban and the provinces/states who did not have the ban might affect the effect of the ban on smoking participation. See online supplementary appendix for formula for the constructs of this exposure measure variable.

\section{Control variables for other policies}

The WHO FCTC, one of the United Nations' most widely embraced treaties, was adopted in May 2003 and came into force on February 2005. To support treaty implementation, WHO developed the MPOWER package, focused on six effective and cost-effective tobacco control measures: $\mathrm{M}$ (monitor tobacco use), $\mathrm{P}$ (protect people from smoke), $\mathrm{O}$ (offer help to quit), W (warn about the dangers of tobacco), $\mathrm{E}$ (enforce bans on tobacco marketing) and R (raise taxes on tobacco). ${ }^{1920}$ All WHO member states were assessed based on their performance implementing each measure. The six MPOWER scores were categorised into four or five levels. For $\mathrm{M}$, the score value ranges from 1 to 4: 1 represents no known data/no recent data/no national representative data, and 2-4 represent the weakest to the strongest level of monitoring. ${ }^{21}$ For the other five policy dimensions (POWER), the scores measure overall strength on a scale of 1-5: 1 represents a lack of data (missing data), and 2-5 represent the weakest to the strongest policies. Since the MPOWER scores were not reported, the scores in the prior years $(2008,2010$ and 2012) were replaced using the scores in years 2009, 2011 and 2013, assuming that no policy changes occurred. Following previous literature, ${ }^{22}$ we constructed a composite score for each country and year by summing up each individual score and used it to account for tobacco control environment.

\section{Price variable}

Country's annual average price of one pack of 20 cigarettes came from Economist Intelligence Unit (EIU) dataset. In addition, the MPOWER dataset also contains the information on cigarette prices for a 20 -cigarette pack of the most sold brand in 2007-2008, 2010, 2012 and 2014. A linear interpolation of cigarette prices from 2007 to 2014 was applied to fill out the cigarette prices for years 2009, 2011 and 2013. Prices were converted to international dollars using the Purchasing Power Parity (PPP) exchange rate and Consumer Price Index (CPI). Finally, the R score in the MPOWER package can be used as a proxy for cigarette prices because raising taxes would lead to an increase in prices.

\section{Control variables for demographics}

Country-level characteristics, such as gross domestic product (GDP) per capita, per cent of population who are female, per cent of population aged 15-64 and per cent of population aged $\geq 65$, were drawn from the World Bank's World Development Indicators (WDI) database. GDP per capita is defined as GDP per capita converted to international dollars using the PPP exchange rates and CPI.

To compile the final sample for the regression analysis, we linked the Euromonitor International, WHO MPOWER package, EIU mean cigarette prices and WDI country-level demographic characteristic data using country and year identifiers. The sample size varies depending on which price measure is used in the regression. 


\section{Methodology}

Smoking prevalence is measured as the percentage of adult population who were daily smokers, and thus is a bounded variable with restricted values from 0 to 1 . As a result, a Fractional Logit Model, a type of generalised linear model with a logit link, was used as the regression method. To explore the causal link between POS display bans and smoking prevalence, a two-way fixed effect model with country and year fixed effects was used. Country fixed effects controlled for time-invariant country-specific unobservables, whereas year fixed effects controlled for common trends across countries. To account for intertemporal correlations within the same country, all regressions were clustered at country level and conducted using Stata V.14.1.

Furthermore, we controlled for a set of country-level timevarying factors that may impact smoking, including the socioeconomic and demographic characteristics described in Table 1, such as GDP per capita, per cent of population aged 15-64 and per cent of population aged $\geq 65$.

The benchmark models in this study used EIU cigarette prices as they are collected annually and thus are less likely to contain measurement errors. Nonetheless, cigarette prices for the most popular brand and R score in the MPOWER package were used as alternative price measures to control for the effects of prices. The three measures together encompass average prices across tiers (EIU), modal prices (most popular brand) and the magnitude of taxes (tax as a percentage of prices). Because prices are arguably the most effective tobacco control policy, ${ }^{23}$ three different specifications with alternative price measures were estimated separately. In specifications with $\mathrm{R}$ score as the price measure, the $\mathrm{R}$ score was incorporated into the composite MPOWER score. In the specifications using EIU or MPOWER prices, the composite MPOWER scores were calculated by taking off the $\mathrm{R}$ scores. Price elasticity was reported using Stata command 'eyex', measuring changes of smoking prevalence in response to price changes.

\section{Sensitivity analysis}

We conducted three sensitivity tests. First, we excluded Australia and Canada from the analysis because POS display bans were initiated at the local level. Second, we excluded the UK from the analysis because the ban in its first years did not cover all types of stores. Last, we excluded Australia, Canada and the UK from the analysis to examine the effect in countries with complete national bans.

\section{RESULTS}

\section{Summary statistics}

The sample size varied depending on what price measure was used in the regression (table 1). For the regressions that used the $\mathrm{R}$ score and the most popular price in MPOWER package, the sample consisted of data from 77 countries. For the regression that used the mean price from the EIU data, the sample consisted of data from 59 countries. The average smoking prevalence in all three samples was roughly the same: $24 \%$ among the total adult population, $33 \%$ among adult males and $15 \%$ among adult females. About $12 \%$ of country-year observations had a POS display ban in place. The average price per 20-cigarette pack from the EIU data was 5.42 international dollars, a little higher than 4.04 international dollars, the average price for the most popular brand from the MPOWER package. The mean composite MPOWER score was about 20.6, and the mean composite MPOWE scores with R score taken off were 17.2 and 16.7 for the EIU price sample and the MPOWER price sample, respectively.

\section{Regression results}

Smoking prevalence among the total $/$ male/female population decreased as the exposure to a POS display ban increased. A full implementation of a ban reduces smoking prevalence among the total, male and female populations by $7 \%, 5 \%$ and $9 \%$. The composite MPOWER score significantly reduced smoking prevalence among males, as well as in the total population. A greater per cent of population aged 15-64 is associated with increased smoking prevalence among the total and male populations. GDP per capita and per cent of population aged $\geq 65$ are not significantly related to smoking prevalence (table 2 ).

Having a POS display ban decreased overall adult, male and female smoking by about 7\%, 6\% and 9\%, respectively. Cigarette price significantly reduced smoking prevalence for all populations, with price elasticity being $-0.06,-0.06$ and -0.08 for total, male and female populations, implying that a $10 \%$ increase in cigarette prices would lead to a $0.6 \%, 0.6 \%$ and $0.8 \%$ decrease in smoking prevalence among total, male and female populations, respectively (table 3 ).

Table 1 Summary statistics

\begin{tabular}{lccc}
\hline 2007-2014 period & $\begin{array}{l}\text { Regression using R score as price } \\
\text { measure }\end{array}$ & $\begin{array}{l}\text { Regression using EIU mean price as } \\
\text { price measure }\end{array}$ & $\begin{array}{l}\text { Regression using MPOWER MP as } \\
\text { price measure }\end{array}$ \\
\hline Smoking prevalence among total population, \% (SD) & $24.4(0.077)$ & $23.3(0.074)$ & $24.3(0.078)$ \\
\hline Smoking prevalence among male population, \% (SD) & $33.8(0.121)$ & $32.0(0.119)$ & $33.7(0.121)$ \\
Smoking prevalence among female population, \% (SD) & $15.3(0.090)$ & $14.8(0.085)$ & $15.3(0.090)$ \\
POS display bans, \% (SD) & $12.0(0.316)$ & $12.3(0.318)$ & $12.1(0.317)$ \\
EIU mean price & & $5.420(2.135)$ & $4.041(2.242)$ \\
MPOWER price for the most popular brand & $20.604(3.644)$ & & $16.694(3.209)$ \\
Composite MPOWER score & & $17.162(2.841)$ & $2.304(1.608)$ \\
Composite MPOWER score with R score taken off & $2.308(1.601)$ & $2.583(1.700)$ & $66.648(4.597)$ \\
GDP per capita in 10 thousands & $66.693(4.604)$ & $66.387(4.890)$ & $11.349(5.746)$ \\
\hline Per cent of population aged 15-64 & $11.335(5.722)$ & $11.483(5.887)$ & 607 \\
\hline Per cent of population aged $\geq 65$ & 613 & 463 & 77 \\
\hline Observations $(\mathrm{n})$ & 77 & 59 & \\
\hline Countries $(\mathrm{n})$ & & & \\
\hline
\end{tabular}

EIU, Economist Intelligence Unit; GDP, gross domestic product; MP, most popular brand; POS, point of sale. 
Table 2 The effect of POS display bans on smoking prevalence using R score as price measure

\begin{tabular}{|c|c|c|c|}
\hline Variables & Smoking prevalence & Smoking prevalence among males & Smoking prevalence among females \\
\hline POS display bans & $\begin{array}{l}-0.086^{*} \\
(-2.38) \\
{[-0.015]} \\
\{-0.065\}\end{array}$ & $\begin{array}{l}-0.078^{*} \\
(-2.00) \\
{[-0.016]} \\
\{-0.052\}\end{array}$ & $\begin{array}{l}-0.105^{* *} \\
(-2.64) \\
{[-0.013]} \\
\{-0.089\}\end{array}$ \\
\hline Composite MPOWER score & $\begin{array}{l}-0.008^{*} \\
(-2.15)\end{array}$ & $\begin{array}{l}-0.009^{*} \\
(-2.41)\end{array}$ & $\begin{array}{l}-0.008 \\
(-1.58)\end{array}$ \\
\hline GDP per capita in 10 thousands & $\begin{array}{l}-0.010 \\
(-0.30)\end{array}$ & $\begin{array}{l}0.003 \\
(0.09)\end{array}$ & $\begin{array}{l}-0.016 \\
(-0.35)\end{array}$ \\
\hline Per cent of population aged 15-64 & $\begin{array}{l}0.017 \dagger \\
(1.95)\end{array}$ & $\begin{array}{l}0.025^{* *} \\
(2.68)\end{array}$ & $\begin{array}{l}0.009 \\
(0.59)\end{array}$ \\
\hline Per cent of population aged $\geq 65$ & $\begin{array}{l}-0.026 \\
(-1.39)\end{array}$ & $\begin{array}{l}-0.026 \\
(-1.28)\end{array}$ & $\begin{array}{l}-0.016 \\
(-0.52)\end{array}$ \\
\hline Observations (n) & 613 & 613 & 613 \\
\hline Countries (n) & 77 & 77 & 77 \\
\hline
\end{tabular}

t-Statistics are in parentheses. SEs were clustered at the country level. Marginal effects are in square brackets. Per cent reduction in smoking prevalence and price elasticities are in curly brackets.

${ }^{*} \mathrm{P}<0.05,{ }^{* * *} \mathrm{P}<0.001, \mathrm{P} P<0.1$.

GDP, gross domestic product; POS, point of sale.

When using cigarette prices for the most popular brand as the price measure, the effect of a POS display ban on smoking prevalence was significant for total, male and female populations. However, the effect of cigarette price on smoking prevalence was only significant for total and male smoking. The implied price elasticities are $-0.07,-0.08$ and -0.04 for total, male and female smoking, respectively (table 4).

\section{Sensitivity analysis}

First, when we exclude Australia and Canada from the analysis, we observe an increase in the magnitude of the coefficients for the exposure to a POS display ban, which implied that having a national display ban would have a greater influence on smoking participation. When we exclude the UK from the analysis, the estimates of the exposure to a POS display ban are almost the same as the original analysis. Since the UK instituted the partial POS display ban in April 2012 and the sales revenues realised in large stores from 2012 to 2014 were about 28\%, the effect of POS display ban on smoking participation was expected to be small. Thus, the estimates did not change much when excluding the UK from the analysis. When we exclude Australia, Canada and the UK from the analysis, we also observe an increase in the coefficients of the exposure to a POS display ban (table 5).

\section{DISCUSSION}

POS tobacco product displays have been linked to increased purchasing and use of cigarettes, and have been increasingly used by the tobacco industry as a major channel for tobacco product marketing. ${ }^{18}$ In recent years, a growing number of countries have implemented POS display bans aimed at curbing the impacts of these displays. However, to date, very limited evidence exists on the effectiveness of such bans. This study filled this research gap by estimating the effects of POS display bans on smoking prevalence among adults, using a cross-country comparison between

Table 3 The effect of POS display bans on smoking prevalence using EIU mean price as price measure

\begin{tabular}{|c|c|c|c|}
\hline Variables & Smoking prevalence & Smoking prevalence among male & Smoking prevalence among female \\
\hline POS display bans & $\begin{array}{l}-0.093^{*} \\
(-2.22) \\
{[-0.016]} \\
\{-0.072\}\end{array}$ & $\begin{array}{l}-0.086 t \\
(-1.90) \\
{[-0.017]} \\
\{-0.058\}\end{array}$ & $\begin{array}{l}-0.106^{*} \\
(-2.35) \\
{[-0.013]} \\
\{-0.091\}\end{array}$ \\
\hline EIU mean price & $\begin{array}{l}-0.015^{* *} \\
(-2.60) \\
{[-0.003]} \\
\{-0.063\}\end{array}$ & $\begin{array}{l}-0.016^{*} \\
(-2.48) \\
{[-0.003]} \\
\{-0.062\}\end{array}$ & $\begin{array}{l}-0.018^{*} \\
(-1.93) \\
{[-0.002]} \\
\{-0.082\}\end{array}$ \\
\hline Composite MPOWER score with R score taken off & $\begin{array}{l}-0.011^{* *} \\
(-2.82)\end{array}$ & $\begin{array}{l}-0.012^{* *} \\
(-2.69)\end{array}$ & $\begin{array}{l}-0.014^{*} \\
(-2.47)\end{array}$ \\
\hline GDP per capita in 10 thousands & $\begin{array}{l}0.003 \\
(0.10)\end{array}$ & $\begin{array}{l}0.019 \\
(0.58)\end{array}$ & $\begin{array}{l}-0.003 \\
(-0.08)\end{array}$ \\
\hline Per cent of population aged $15-64$ & $\begin{array}{l}0.023^{*} \\
(2.36)\end{array}$ & $\begin{array}{l}0.032^{* *} \\
(3.12)\end{array}$ & $\begin{array}{l}0.017 \\
(0.94)\end{array}$ \\
\hline Per cent of population aged $\geq 65$ & $\begin{array}{l}0.009 \\
(0.36)\end{array}$ & $\begin{array}{l}0.012 \\
(0.45)\end{array}$ & $\begin{array}{l}0.021 \\
(0.53)\end{array}$ \\
\hline Observations (n) & 463 & 463 & 463 \\
\hline Countries (n) & 59 & 59 & 59 \\
\hline
\end{tabular}

t-Statistics are in parentheses. SEs were clustered at the country level. Marginal effects are in square brackets. Per cent reduction in smoking prevalence and elasticities are in curly brackets.

${ }^{*} \mathrm{P}<0.05,{ }^{* * *} \mathrm{P}<0.001, \mathrm{P}<0.1$

EIU, Economist Intelligence Unit; GDP, gross domestic product; POS, point of sale. 


\begin{tabular}{|c|c|c|c|}
\hline Variables & Smoking prevalence & Smoking prevalence among male & Smoking prevalence among female \\
\hline POS display bans & $\begin{array}{l}-0.077^{*} \\
(-2.13) \\
{[-0.014]} \\
\{-0.058\}\end{array}$ & $\begin{array}{l}-0.067 \dagger \\
(-1.78) \\
{[-0.014]} \\
\{-0.045\}\end{array}$ & $\begin{array}{l}-0.100^{*} \\
(-2.38) \\
{[-0.012]} \\
\{-0.084\}\end{array}$ \\
\hline MPOWER price for the most popular brand & $\begin{array}{l}-0.024 \dagger \\
(-1.71) \\
{[-0.004]} \\
\{-0.073\}\end{array}$ & $\begin{array}{l}-0.030 \dagger \\
(-1.88) \\
{[-0.006]} \\
\{-0.083\}\end{array}$ & $\begin{array}{l}-0.013 \\
(-0.71) \\
{[-0.002]} \\
\{-0.043\}\end{array}$ \\
\hline Composite MPOWER score with R score taken off & $\begin{array}{l}-0.008 \dagger \\
(-1.82)\end{array}$ & $\begin{array}{l}-0.009^{*} \\
(-2.16)\end{array}$ & $\begin{array}{l}-0.008 \\
(-1.30)\end{array}$ \\
\hline GDP per capita in 10 thousands & $\begin{array}{l}-0.001 \\
(-0.02)\end{array}$ & $\begin{array}{l}0.014 \\
(0.39)\end{array}$ & $\begin{array}{l}-0.009 \\
(-0.19)\end{array}$ \\
\hline Per cent of population aged $15-64$ & $\begin{array}{l}0.014 \\
(1.48)\end{array}$ & $\begin{array}{l}0.023^{*} \\
(2.23)\end{array}$ & $\begin{array}{l}0.005 \\
(0.31)\end{array}$ \\
\hline Per cent of population aged $\geq 65$ & $\begin{array}{l}-0.019 \\
(-0.94)\end{array}$ & $\begin{array}{l}-0.014 \\
(-0.64)\end{array}$ & $\begin{array}{l}-0.017 \\
(-0.52)\end{array}$ \\
\hline Observations (n) & 607 & 607 & 607 \\
\hline Countries ( $n$ ) & 77 & 77 & 77 \\
\hline
\end{tabular}

t-Statistics are in parentheses. SEs were clustered at the country level. Marginal effects are in square brackets. Per cent reduction in smoking prevalence and elasticities are in curly brackets.

${ }^{*} \mathrm{P}<0.05,+\mathrm{P}<0.1$.

GDP, gross domestic product; POS, point of sale.

countries with and without such bans. Moreover, as multiple countries implemented POS display bans at different times, we were able to capitalise on this variation to estimate the causal link between POS display bans and smoking prevalence using a two-way fixed effects approach.

We estimated that POS display bans significantly reduce contemporaneous smoking prevalence among total adult population, adult males and adult females by $7 \%, 6 \%$ and $9 \%$, respectively. These effects are in general smaller than existing estimates of the association between POS promotion and cigarette purchasing. For example, Li et al suggested that smokers residing in an area with a display ban were $60 \%$ less likely to make an impulse purchase. ${ }^{14}$ This study differs from these previous studies on impulse purchasing by examining the margin

Table 5 Sensitivity analysis results for regression of smoking prevalence among total population

\begin{tabular}{|c|c|c|c|c|}
\hline Control variables & Smoking prevalence & $\begin{array}{l}\text { Sensitivity test } 1 \\
\text { (excluding Canada and Australia) }\end{array}$ & $\begin{array}{l}\text { Sensitivity test } 2 \\
\text { (excluding the UK) }\end{array}$ & $\begin{array}{l}\text { Sensitivity test } 3 \\
\text { (excluding Australia, Canada } \\
\text { and the UK) }\end{array}$ \\
\hline \multicolumn{5}{|l|}{ Panel A: using $R$ score as price measure } \\
\hline POS display bans & $\begin{array}{l}-0.086^{*} \\
(-2.38) \\
{[-0.015]} \\
\{-0.065\}\end{array}$ & $\begin{array}{l}-0.095^{*} \\
(-2.44) \\
{[-0.017]} \\
\{-0.072\}\end{array}$ & $\begin{array}{l}-0.086^{*} \\
(-2.36) \\
{[-0.015\}} \\
\{-0.065\}\end{array}$ & $\begin{array}{l}-0.095^{*} \\
(-2.42) \\
{[-0.017]} \\
\{-0.072\}\end{array}$ \\
\hline \multicolumn{5}{|l|}{ Panel B: using EIU mean price as price measure } \\
\hline POS display bans & $\begin{array}{l}-0.093^{*} \\
(-2.22) \\
{[-0.016]} \\
\{-0.072\}\end{array}$ & $\begin{array}{l}-0.107^{* *} \\
(-2.35) \\
{[-0.019]} \\
\{-0.082\}\end{array}$ & $\begin{array}{l}-0.093^{*} \\
(-2.21) \\
{[-0.016]} \\
\{-0.071\}\end{array}$ & $\begin{array}{l}-0.107^{*} \\
(-2.34) \\
{[-0.019]} \\
\{-0.082\}\end{array}$ \\
\hline EIU mean price & $\begin{array}{l}-0.015^{* *} \\
(-2.60) \\
{[-0.003]} \\
\{-0.063\}\end{array}$ & $\begin{array}{l}-0.018^{* *} \\
(-3.13) \\
{[-0.003]} \\
\{-0.073\}\end{array}$ & $\begin{array}{l}-0.015^{* *} \\
(-2.64) \\
{[-0.003]} \\
\{-0.064\}\end{array}$ & $\begin{array}{l}-0.018^{* * *} \\
(-3.19) \\
{[-0.003]} \\
\{-0.074\}\end{array}$ \\
\hline \multicolumn{5}{|c|}{ Panel C: using MPOWER price for the most popular brand as price measure } \\
\hline POS display bans & $\begin{array}{l}-0.077^{*} \\
(-2.13) \\
{[-0.014]} \\
\{-0.058\}\end{array}$ & $\begin{array}{l}-0.085^{*} \\
(-2.27) \\
{[-0.015]} \\
\{-0.064\}\end{array}$ & $\begin{array}{l}-0.077^{*} \\
(-2.11) \\
{[-0.014]} \\
\{-0.058\}\end{array}$ & $\begin{array}{l}-0.084^{*} \\
(-2.26) \\
{[-0.015]} \\
\{-0.064\}\end{array}$ \\
\hline MPOWER price for the most popular brand & $\begin{array}{l}-0.024 \dagger \\
(-1.71) \\
{[-0.004]} \\
\{-0.073\}\end{array}$ & $\begin{array}{l}-0.034^{* *} \\
(-2.57) \\
{[-0.006]} \\
\{-0.103\}\end{array}$ & $\begin{array}{l}-0.024 \dagger \\
(-1.72) \\
{[-0.004]} \\
\{-0.072\}\end{array}$ & $\begin{array}{l}-0.035^{* *} \\
(-2.59) \\
{[-0.006]} \\
\{-0.103\}\end{array}$ \\
\hline
\end{tabular}

t-Statistics are in parentheses. SEs were clustered at the country level. Marginal effects are in square brackets. Per cent reduction in smoking prevalence and elasticities are in curly brackets.

${ }^{*} \mathrm{P}<0.05,{ }^{* *} \mathrm{P}<0.01,{ }^{* *} \mathrm{P}<0.001,+\mathrm{P}<0.1$.

EIU, Economist Intelligence Unit; POS, point of sale. 
of smoking prevalence. The reduction of smoking prevalence can only happen through preventing smoking or encouraging quitting, rather than cutting consumption by refraining from impulse purchases. The effects of POS may be smaller as a result. ${ }^{18}$ These estimated effects also are smaller than the estimated association between POS ad bans and youth smoking. ${ }^{10} 11$ The difference in estimates between adults and youth suggests that youth experimenting with smoking are more susceptible to the persuasive effects of POS displays. As a result, POS promotion and marketing restrictions such as display bans may have a greater impact on youth smoking prevalence than on adult prevalence. Furthermore, studies of the association between POS marketing and promotion restrictions and smoking behaviours may overstate the effects of these bans as country-specific unobservables that may bias the estimates that were not controlled for. ${ }^{16} 17$

This study is also the first study that investigates the longterm impact of POS display bans on adults' smoking prevalence using aggregated longitudinal data. McNeill examined the smoking prevalence among youths or adults 6 months after the POS display ban in Ireland and did not find significant changes in prevalence among youths or adults. Because a change in smoking prevalence/consumption is reflective of a combination of factors, the finding of no changes would not necessarily illustrate that POS display bans have no effect on smoking prevalence/consumption. Furthermore, a simple comparison, without taking into account the exposure to policies and the time window for policies to change behaviour, likely understates the effect of the policy.

Sensitivity tests that look only at countries with national bans or comprehensive bans tend to yield larger effect estimates, suggesting that a more comprehensive display ban that covers all locations, or all locations and store types in a country, has greater impact than a local or partial ban. In addition, when estimating the effects, we controlled for important factors such as the tobacco control environment and price of cigarettes. Consistent with the existing literature, we found that a stronger tobacco control environment and higher prices significantly reduced smoking prevalence. ${ }^{23}$

Result by gender further shows that the reduction in smoking prevalence due to POS display bans was greater for women than for men. This finding is consistent with that from Shang et al where the authors found a greater association between POS advertising bans and reduced smoking for girls than for boys. ${ }^{24}$ The combined results suggest that POS marketing restrictions may have a greater impact on reducing female smoking than male smoking. This suggests that a comprehensive ban on POS tobacco marketing is key to reducing smoking in populations with different demographic characteristics.

This study has several limitations. First, bans on POS advertising and display were instituted at the same time in some countries. It is not possible to disentangle smoking prevalence from the independent effects of a POS display ban and a concurrent advertising ban. Second, other country-specific tobacco control measures, such as mass media antismoking campaign and programmes, bans on smoking in certain places, health warning label and cigarette pack size, may have confounded the results. To minimise the confounding effects, we incorporated six MPOWER policy indices into the analysis to capture the overall performance on these policy fields. Finally, future research may evaluate the long-term effect of POS display bans by examining how the length of the policies (ie, years since implementation) influences smoking outcomes.

\section{CONCLUSION}

We examined the effect that POS display bans have on smoking prevalence using Euromonitor International and WHO MPOWER data for 2007-2014 from 77 countries. Results show that having a POS display ban can decrease overall smoking, male smoking and female smoking by about $7 \%, 6 \%$ and $9 \%$, respectively. As part of a comprehensive tobacco control strategy, bans on POS display have been implemented in 20 countries as of 2016. The public health benefits of POS display bans through reducing smoking should encourage other countries without a POS display ban to adopt such a policy.

\section{What this paper adds}

- Using aggregated country-level longitudinal data from 77 countries in the world from 2007 to 2014, and a two-way fixed effects model, we found that point-of-sale (POS) display bans significantly reduced daily smoking prevalence among adults.

- POS displays are associated with increased cigarette purchases. However, evidence on the association between POS display bans and reduced smoking prevalence/cigarette consumption is mixed.

- Existing studies either presented descriptive statistics or estimated associations between POS display bans and smoking behaviours, and as a result, did not analyse the causal impact of POS display bans on smoking. This is the first study to our knowledge that examines the causal impact of POS display bans on smoking prevalence.

- Having a POS display ban reduced overall adult daily smoking, male smoking and female smoking by about $7 \%$, $6 \%$ and $9 \%$, respectively.

- Having a POS display ban is likely to reduce smoking prevalence and generate public health benefits.

Contributors $\mathrm{YH}$ conducted the analyses and wrote the manuscript. CS, JH, K-WC and FJC contributed to study design and reports interpretation. The findings and conclusions in this article are those of the authors.

Funding Research reported in this publication was supported by grant number P50DA036128 from the NIH/NIDA and FDA Center for Tobacco Products (CTP).

Disclaimer The content is solely the responsibility of the authors and does not necessarily represent the official views of the NIH or the Food and Drug Administration.

Competing interests None declared.

Provenance and peer review Not commissioned; externally peer reviewed.

(c) Article author(s) (or their employer(s) unless otherwise stated in the text of the article) 2018. All rights reserved. No commercial use is permitted unless otherwise expressly granted.

\section{REFERENCES}

1 World Health Organization. Global progress report on implementation of the WHO framework convention on tobacco control, 2012

2 Spanopoulos D, Ratschen E, McNeill A, et al. Retail price and point of sale display of tobacco in the UK: a descriptive study of small retailers. PLoS One 2012;7:e29871.

3 Bach L. Tobacco Marketing That Reaches Kids. Washington, DC: Point-of-sale Advertising and Promotions, 2016.

4 Federal Trade Commission. Federal trade commission cigarette report for 2014. 2016 https://www.ftc.gov/system/files/documents/reports/federal-trade-commissioncigarette-report-2014-federal-trade-commission-smokeless-tobacco-report/ftc cigarette_report_14.pdf (accessed 11 Mar 2017).

5 Euromonitor International. Euromonitor international cigarette country report. http:// www.euromonitor.com/cigarettes (accessed 11 Mar 2017).

6 Wakefield M, Germain D, Henriksen L. The effect of retail cigarette pack displays on impulse purchase. Addiction 2008;103:322-8.

7 Clattenburg EJ, Elf JL, Apelberg BJ. Unplanned cigarette purchases and tobacco point of sale advertising: a potential barrier to smoking cessation. Tob Control 2013;22:376-81. 
8 Health Canada. Canadian Tobacco Use Monitoring Survey (CTUMS). 2011 https:// www.canada.ca/en/health-canada/services/publications/healthy-living/canadiantobacco-use-monitoring-survey-ctums-2011.html (accessed 11 Mar 2017).

9 Statistics Iceland. Smoking habits of 15-79 years old 1987-2015. http://px.hagstofa. is/pxen/pxweb/en/Samfelag/Samfelag__heilbrigdismal_lifsvenjur_heilsa_ afengiogreyk/HEI07101.px (accessed 11 Mar 2017).

10 Shang C, Huang J, Li Q, et al. The Association between point-of-sale advertising bans and youth experimental smoking: findings from the Global Youth Tobacco Survey (GYTS). AIMS Public Health 2015;2:832-44.

11 Shang C, Huang J, Cheng KW, et al. Global evidence on the association between pos advertising bans and youth smoking participation. Int J Environ Res Public Health 2016;13:306.

12 Wakefield M, Germain D. Adult smokers' use of point-of-sale displays to select cigarette brands. Aust N Z J Public Health 2006;30:483-4.

13 Carter OB, Phan T, Mills BW. Impact of a point-of-sale tobacco display ban on smokers' spontaneous purchases: comparisons from postpurchase interviews before and after the ban in Western Australia. Tob Control 2015;24(e1):e81-e86.

14 Li L, Borland R, Fong GT, et al. Impact of point-of-sale tobacco display bans: findings from the international tobacco control four country survey. Health Educ Res 2013;28:898-910.

15 Scheffels J, Lavik R. Out of sight, out of mind? Removal of point-of-sale tobacco displays in Norway. Tob Control 2013;22:e37-42.
16 McNeill A, Lewis S, Quinn C, et al. Evaluation of the removal of point-of-sale tobacco displays in Ireland. Tob Control 2011;20:137-43.

17 Quinn C, Lewis S, Edwards R, et al. Economic evaluation of the removal of tobacco promotional displays in Ireland. Tob Control 2011;20:039602.

18 Robertson L, McGee R, Marsh L, et al. A systematic review on the impact of point-ofsale tobacco promotion on smoking. Nicotine Tob Res 2015;17:2-17.

19 World Health Organization. WHO report on the global tobacco epidemic: the MPOWER package. Geneva: World Health Organization, 2008.

20 World Health Organization. Mpower, six policies to reverse the tobacco epidemic. WHO report on the global tobacco epidemic. Geneva: World Health Organization, 2008.

21 World Health Organization. WHO report on the global tobacco epidemic, 2013: enforcing bans on tobacco advertising, promotion and sponsorship. Geneva: World Health Organization, 2013.

22 Ngo A, Cheng KW, Chaloupka FJ, et al. The effect of MPOWER scores on cigarette smoking prevalence and consumption. Prev Med 2017;105S:S10-14.

23 Chaloupka FJ, Straif K, Leon ME. Working Group, International Agency for Research on Cancer. Effectiveness of tax and price policies in tobacco control. Tob Control 2011;20:235-8.

24 Shang C, Huang J, Li Q, et al. The association between point-of-sale advertising bans and youth experimental smoking: findings from the Global Youth Tobacco Survey (GYTS). AIMS Public Health 2015;2:832-44. 